\title{
Análise da cadeia de valor: um estudo no âmbito da gestão estratégica de custos de empresas da construção civil da grande Porto Alegre
}

Value chain analysis: a study in the scope of strategic cost management of civil construction companies of great Porto Alegre region

\section{Marcos Antonio Souza}

Doutor em Controladoria e Contabilidade - FEA/USP

Professor do Curso de Mestrado em Ciências Contábeis da Unisinos

Endereço: Av. Unisinos, 950, Bairro Cristo Rei, Centro de Ciências Econômicas, Sala 5A401a

CEP 93022-000 - São Leopoldo/RS - Brasil

Email: marcosas@unisinos.br

Telefone: (51) 3037-1000, Ramal 1580

\section{Eliane Mello}

Mestranda em Ciências Contábeis - UNISINOS

Endereço: Av. Unisinos, 950, Bairro Cristo Rei, Centro de Ciências Econômicas, Sala 5A401a

CEP 93022-000 - São Leopoldo/RS - Brasil

Email: eliane.mello@isiscontabilidade.com.br

Telefone: (51) 3037-1000, Ramal 1580 


\title{
Resumo
}

O objetivo do artigo é identificar o uso da análise da cadeia de valor na gestão estratégica de custos de empresas da construção civil. O estudo considera a cadeia de valor como um dos pilares da gestão estratégica de custos. Trata-se de um estudo exploratório, descritivo e qualitativo, realizado com a adoção da análise múltipla de casos e desenvolvido com três empresas gaúchas de médio porte estabelecidas no Vale do Rio dos Sinos. A coleta de dados foi realizada no terceiro trimestre de 2009, por meio de entrevistas com executivos das empresas participantes. Os principais resultados indicam que as empresas pesquisadas realizam a análise da cadeia de valor de forma superficial, não explorando todos os benefícios que ela pode oferecer à condução da gestão estratégica de custos. Constata-se o uso de tradicionais ações de reduções de custos e da frágil exploração das possíveis relações com fornecedores e clientes.

Palavras-chave: Gestão estratégica. Cadeia de valor. Gestão de custos. Construção civil..

\begin{abstract}
The article aims to identify the use of value chain analysis in the scope of strategic cost management (SCM) of civil construction companies. The study assumption is that the value chain is one of SCM pillars. This is an exploratory, descriptive and qualitative study, carried out with adoption of multiple case studies developed based on three middles companies established in the Vale do Rio dos Sinos region. The data was collected in the third trimester of 2009 interviews with executives of the participant companies. The main results indicate that the adoption of value chain analysis by the searched companies exist only in superficial form, not exploring all the benefits that it can offer to the conduction of strategic cost management. The use of traditional practices about reduction costs is an evidence of the fragile exploration of the possible relations with suppliers and customers.
\end{abstract}

Keywords: Strategic management. Value chain. Cost management. Civil construction.

\section{INTRODUÇÃO}

Num mercado cada vez mais globalizado, deter capacidade competitiva tornou-se uma das prioridades para que as empresas assegurem uma continuidade sustentável. Para tanto, elas devem desenvolver e implantar estratégias eficazes, que consigam agregar valor aos clientes e, simultaneamente, remunerar adequadamente os proprietários.

A gestão estratégica de custos - GEC tem sido um dos recursos gerenciais que as empresas têm utilizado para conseguir sucesso no desempenho das suas atividades. Porter (1989) destaca que o sucesso dos negócios passa, também, pela capacidade da empresa em gerir de forma eficiente e eficaz as suas atividades internas e articular-se externamente como um dos agentes que integram um determinado segmento de atividade. Logo, surge na ótica de Porter (1990), o entendimento básico da cadeia de valor, seja ela interna ou externa.

Shank e Govindarajan (1997) desenvolveram seus estudos a respeito da gestão estratégica de custos a partir de três pilares, a saber: (a) análise da cadeia de valor; (b) análise do posicionamento estratégico; (c) análise dos direcionado- 
res de custos. Os autores destacam que o surgimento da GEC resulta da mistura desses temas, todos eles buscados na literatura relacionada à gestão estratégica. Evidencia-se assim que o surgimento da GEC está diretamente relacionado aos desenvolvimentos de Porter (1990) quanto aos instrumentos de obtenção de vantagem competitiva. Este estudo aborda mais especificamente um desses pilares, a cadeia de valor.

Uma das ferramentas utilizadas pelas organizações para compreender o seu posicionamento e seus inter-relacionamentos com outros agentes econômicos é a análise da cadeia de valor, o que envolve o exame de quatro áreas fundamentais: (1) os processos dentro de uma unidade empresarial; (2) as ligações com fornecedores; (3) as ligações com os clientes; (4) as ligações através da cadeia de valor das unidades internas da organização.

Esse entendimento é referendado e ampliado por Rocha e Borinelli (2007) os quais destacam que para diagnosticar a cadeia de valor é necessário segregá-la em suas atividades relevantes, pois se necessita de uma forte integração entre os agentes da cadeia. Depois de se identificar os estágios, fases e atividades relevantes, deve-se identificar e mensurar os ativos a elas relacionados, as receitas e os custos correspondentes. Isso possibilita a apuração da margem de lucro e da taxa de retorno do investimento de cada atividade, estágio ou de cada entidade.

O levantamento das atividades na cadeia de valor da empresa como forma de gerar informações gerenciais necessárias à identificação e manutenção de vantagens competitivas em relação aos concorrentes, tem sido reconhecido como um fator chave para a gestão estratégica de custos. A respeito disso, Shank e Govindarajan (1997) e Faria e Costa (2005) destacam que não basta a ação isolada de incrementar a eficiência das atividades internas à empresa, sendo também necessário conhecer como as atividades de valor da empresa estão sincronizadas e se integram nas cadeias de valor dos fornecedores e dos clientes.

Partindo-se da premissa de que a compreensão das atividades estratégicas, pelo menos das mais relevantes, dentro da cadeia de valor, leva à compreensão dos custos e à fonte de diferenciação dos produtos e serviços em relação aos concorrentes, este estudo tem como objetivo identificar de que forma esse procedimento de análise da cadeia de valor, no âmbito da gestão estratégica de custos, é adotado por empresas construtoras gaúchas.

Estudos pautados na investigação sobre adoção das práticas relacionadas à GEC têm sido recorrente na literatura da área. Dentre elas têm-se Morelli e Wiberg (2002), Sulaiman, Ahmad e Alwi (2004), Sulaiman, Ahmad e Alwi (2005), Waweru, Hoque e Uliana (2005), Cinquini e Tenucci (2006), Rattray, Lord e Shanahan (2007), Quesado e Rodrigues (2007). A existência de tais pesquisas reflete o interesse que há em se avançar no conhecimento da realidade sobre a efetiva integração dessas práticas como instrumento de gestão das organizações. 
Além disso, a justificativa desse estudo ampara-se no pronunciamento de diversos pesquisadores dessa temática, tais como Gomes (1995), Iudícibus (1996) e Franco (1999). Para eles, os avanços nas estruturas conceituais são relevantes, mas precisam ser validados pelos experimentos reais, desenvolvidos com a colaboração das empresas, até mesmo como tentativa para se evitar que o senso comum prevaleça na apresentação dos novos enfoques, como panacéia para a maioria dos problemas encontrados nos sistemas de gestão das organizações.

A par do pronunciamento desses autores, as pesquisas sobre a adoção efetiva de práticas de gestão, particularmente as de custos, têm dado sua contribuição ao indicar a necessidade de aperfeiçoamento dos novos modelos. É o caso do surgimento do Time-Driven- $\mathrm{ABC}$, um novo modelo para adoção do método de custeio baseado em atividades (ABC). Essa necessidade foi identificada por pesquisas empíricas realizadas com empresas, as quais revelaram as dificuldades na implantação e manutenção do $\mathrm{ABC}$ na sua forma originalmente desenvolvida (KAPLAN e ANDERSON, 2007; VAN DER MERWE, 2009).

Além dessa introdução o estudo contém a exposição do referencial teórico pertinente ao tema, seguido da exposição dos procedimentos metodológicos adotados e da apresentação e análise dos dados. Na sequência têm-se as conclusões do estudo, finalizando com as referências utilizadas no desenvolvimento da pesquisa.

\section{REVISÃO DE LITERATURA}

\subsection{Cadeia de Valor: Conceito e Objetivos}

Seguindo o delineamento de Porter (1986), uma empresa é uma cadeia de valor, representada por uma série de processos inter-relacionados. Assim, para se compreender a empresa é necessária a efetiva compreensão das relações entre os processos que a compõe e, além disso, reconhecer também que uma empresa deve ser vista dentro do contexto de uma cadeia global de atividades, onde é gerado o valor.

Porter (1990) também defende o entendimento de que a cadeia de valor desagrega uma empresa nas suas atividades relevantes para projetar, produzir, comercializar, entregar e sustentar o produto. Este procedimento é necessário para que se possa compreender o comportamento dos custos e as fontes existentes e potenciais de diferenciação. Ainda segundo Porter (1990), a cadeia de valor é o ponto de partida para a gestão estratégica de custos, pois a análise da mesma indicará quais são os elos que agregam mais valor ao produto, que utilizam mais ativos e que consomem mais atividades, propiciando ao gestor oportunidades de direcionar ações de melhorias. 
Nessa mesma linha de entendimento, Silva e Kopittke (2002) argumentam que a cadeia de valor permite conhecer como se estrutura o processo de formação de valor do bem ou serviço, como isso é percebido pelo cliente final e quais seriam os fatores que alterariam o custo ao longo da cadeia. Garrison e Noreen (2000) acrescentam que a cadeia de valor é uma das formas de se analisar os custos e as funções principais que agregam valor aos produtos e serviços de uma empresa, envolvendo a pesquisa e desenvolvimento, projeto, fabricação, marketing e distribuição do produto, visando oferecer o melhor atendimento ao cliente.

A cadeia de valor, para Carvalho e Laurindo (2003, p.111), [...] "é um conjunto de atividades tecnológicas e economicamente distintas que a empresa utiliza para realizar seus negócios". Considerando-se que cada uma destas atividades é uma atividade de valor, tem-se que a capacidade de agregar valor a esta atividade, em relação ao seu concorrente é o pilar da vantagem competitiva.

Completando esses conceitos de cadeia de valor, Rocha e Borinelli (2007, p.4), no contexto da amplitude da cadeia de valor, destacam que ela "[...] é uma seqüência de atividades que se inicia com a origem dos recursos e vai até o descarte do produto pelo último consumidor".

Observa-se, pelos conceitos apresentados, que a cadeia de valor busca enxergar a empresa como um conjunto de atividades inter-relacionadas que busca agregar valor específico ao cliente. Além disso, a compreensão da cadeia de valor torna-se necessária, para consolidar as relações ambientais entre as empresas, na perspectiva da interdependência dos valores e pesos de cada agente econômico, o que impacta no sucesso e na sobrevivência da organização no mercado.

A utilidade da cadeia de valor, dentre outros aspectos, é apontar o modo como uma empresa pode determinar uma estratégia de custos a fim de tornar-se mais competitiva, além de abordar a interação entre custo e diferenciação, numa realidade de atividades desenvolvidas para se conseguir produtos aos anseios dos clientes. Para tanto, torna-se de relevante importância a análise da cadeia de valores no processo de gestão de custos na empresa, uma vez que tal ferramenta oferece condições de apontar e explorar as vantagens competitivas que podem ser agregadas nos produtos ou serviços, tanto do ponto de vista interno (atividades do processo interno da empresa) quanto externo (inserção da empresa na cadeia de valor de seus fornecedores e clientes). Numa visão de maior amplitude, é a conjunção das cadeias de valores das empresas que formam a cadeia de valor global de um determinado segmento.

Segundo Porter (1990), as atividades que compõem a cadeia interna de valor são divididas em dois grupos, conforme apresentado na Figura 1. Um dos grupos representa as atividades primárias e o outro as atividades secundárias ou de apoio. Enquanto as atividades primárias são aquelas que estão ligadas diretamente ao processo de desenvolvimento do produto e transferência para o cliente, as de 
apoio são aquelas que sustentam as atividades primárias. A importância de cada uma dessas atividades de valor difere dependendo da empresa. Cada empresa, estudando suas atividades e o que é valor para seus clientes, conseguirá identificar, em sua cadeia, as atividades com maior potencial para obtenção de vantagens competitivas. Dado que a vantagem competitiva, segundo Tavares (2000, p.327), ocorre "quando a organização consegue criar um valor superior para seus consumidores em relação a seus concorrentes", então o objetivo de se analisar a cadeia é potencializar a que essas atividades de valor funcionem de forma integrada, todas colaborando no seu conjunto com a geração de valor para o cliente.

Figura 1 - Cadeia interna de valor

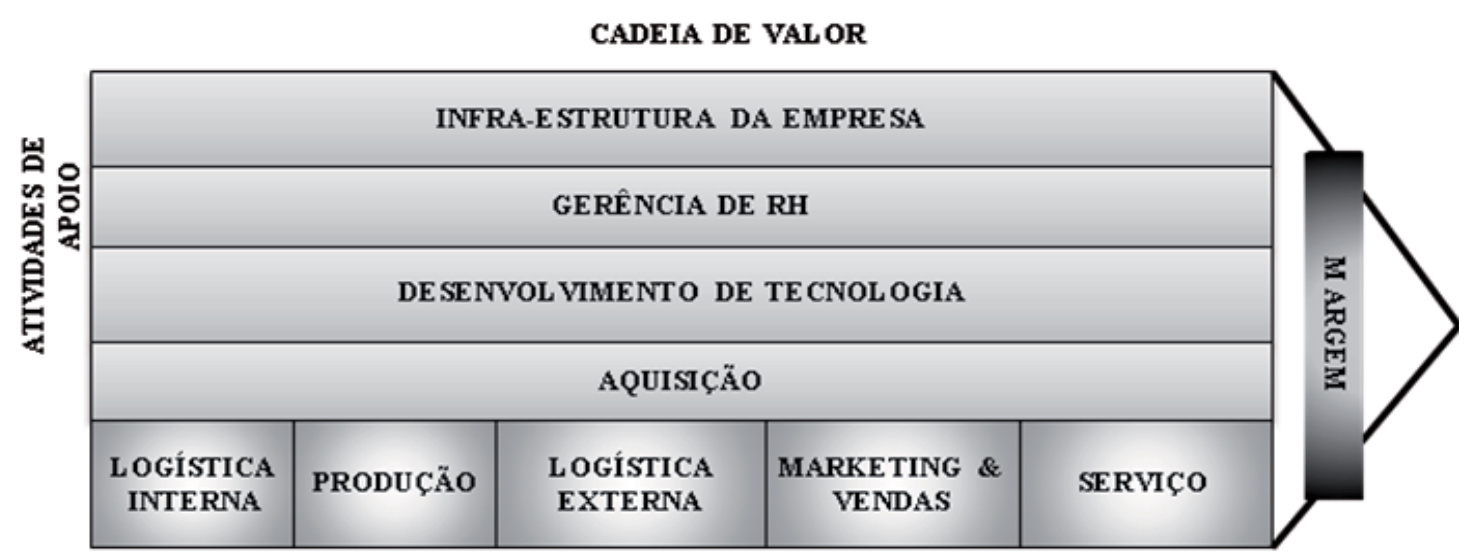

ATIVIDADES PRIMÁRIAS

Fonte: Adaptado de Porter (1990).

\subsection{Análise da Cadeia de Valor}

A análise da cadeia de valor segundo Hansen e Mowen (2001), serve para subsidiar o processo de gerenciamento estratégico da empresa, pois permite compreender e agir sobre a estrutura patrimonial, econômica, financeira e operacional das suas principais atividades, processos e entidades. O objetivo maior é conquistar e manter a vantagem competitiva fornecendo subsídios para o processo de formulação de estratégias e tomada de decisão. A esse respeito, Rocha (1999) destaca as seguintes utilidades da análise da cadeia:

a) Detectar ameaças (exemplo: a entrada de novos e melhores produtos no mercado, a um custo menor que o da empresa);

b) Identificar estágios fortes e fracos de cada produto (elaborando assim estratégias de marketing, vendas e até mesmo a substituição do produto);

c) Detectar oportunidades de diferenciação (com relação ao produto ou serviço do concorrente oferecendo um maior valor agregado ao cliente);

d) Identificar os principais determinantes de custo (verificar as atividades 
que não agregam valor ao produto e, portanto, não essências à sua fabricação, com o intuito de eliminá-las);

e) Verificar as oportunidades de redução de custos;

f) Pode-se comparar a cadeia de valor da empresa com a cadeia de valor do concorrente, sendo que essa análise tem um papel central na gestão estratégica, em decorrência dos impactos que pode provocar nos resultados.

Os passos para análise da cadeia de valor, segundo Hansen e Mowen (2001) são: (a) identificar a cadeia de valor da empresa, os custos, receitas e ativos de cada uma das atividades; (b) analisar os direcionadores de custos dessas atividades; (c) controlar os direcionadores e os custos melhor do que os concorrentes ou até mesmo reconfigurar a cadeia de valor se for necessário.

Para começar a análise, primeiramente é preciso definir a cadeia de valor e as atividades existentes na empresa, visto a dimensão da sua abrangência dentro do processo. Assim, a identificação das atividades se faz necessária, uma vez que no processo operacional de cada uma delas serão agregados valores de insumos, recursos humanos e alguma forma de tecnologia empregada no produto ou serviço.

Após identificar sua cadeia de valor, a empresa deve verificar quais as atividades que agregam valor ao produto e quais as que não agregam, mas que são necessárias a sua produção, visando manter somente as atividades necessárias e, consequentemente, eliminar as demais. Assim, identificadas as atividades, procura-se relacionar a elas os ativos que são utilizados para gerar as receitas e que representam consumo de recursos. Isso possibilita identificar a margem de lucro de cada atividade, bem como o retorno que está sendo conseguido ou que pode sê-lo com o investimento realizado.

Com relação aos cost drivers, ou direcionadores de custo, eles devem ser analisados sob a perspectiva de se entender como eles se comportam e como afetam a estrutura de custos e de controle que podem conduzir a empresa a tomar decisões que viabilizem manter, criar ou modificar sua vantagem competitiva. Portanto, compreender as atividades estratégicas, pelo menos as mais relevantes dentro da cadeia de valor, leva à compreensão das receitas, dos custos e das fontes de diferenciação dos produtos em relação aos concorrentes.

Cada processo possui além da relação de custo e valor dentro da empresa (elos da cadeia interna), também as ligações entre clientes e fornecedores (elos da cadeia externa). Isso significa que existem processos dentro de cada etapa da cadeia produtiva que podem ser melhorados também por meio das relações mantidas com clientes e fornecedores da empresa e até mesmo com seus concorrentes, o que pode ampliar ou minimizar as incertezas do ambiente, dependendo do nível de amadurecimento dessas relações. Assim, quanto mais sólidas forem 
tais relações, normalmente estabelecidas através de contratos, menores serão as incertezas ou as possibilidades de o ambiente concorrencial afetar a dinâmica do mercado da empresa.

$\mathrm{O}$ gerenciamento da cadeia de valores de uma empresa, em relação às cadeias de valores dos concorrentes, determina a possibilidade de desenvolvimento ou manutenção de vantagens de custos dos produtos ou serviços postos para comercialização. Segundo Porter (1990), isto ocorre, porque a sua análise fornece informações básicas para a formação e gestão de custos, permitindo as empresas obterem vantagem em custo de modo sustentável. A Figura 2 apresenta os elos que formam a cadeia externa de valor da empresa.

Figura 2 - A cadeia Externa de Valor

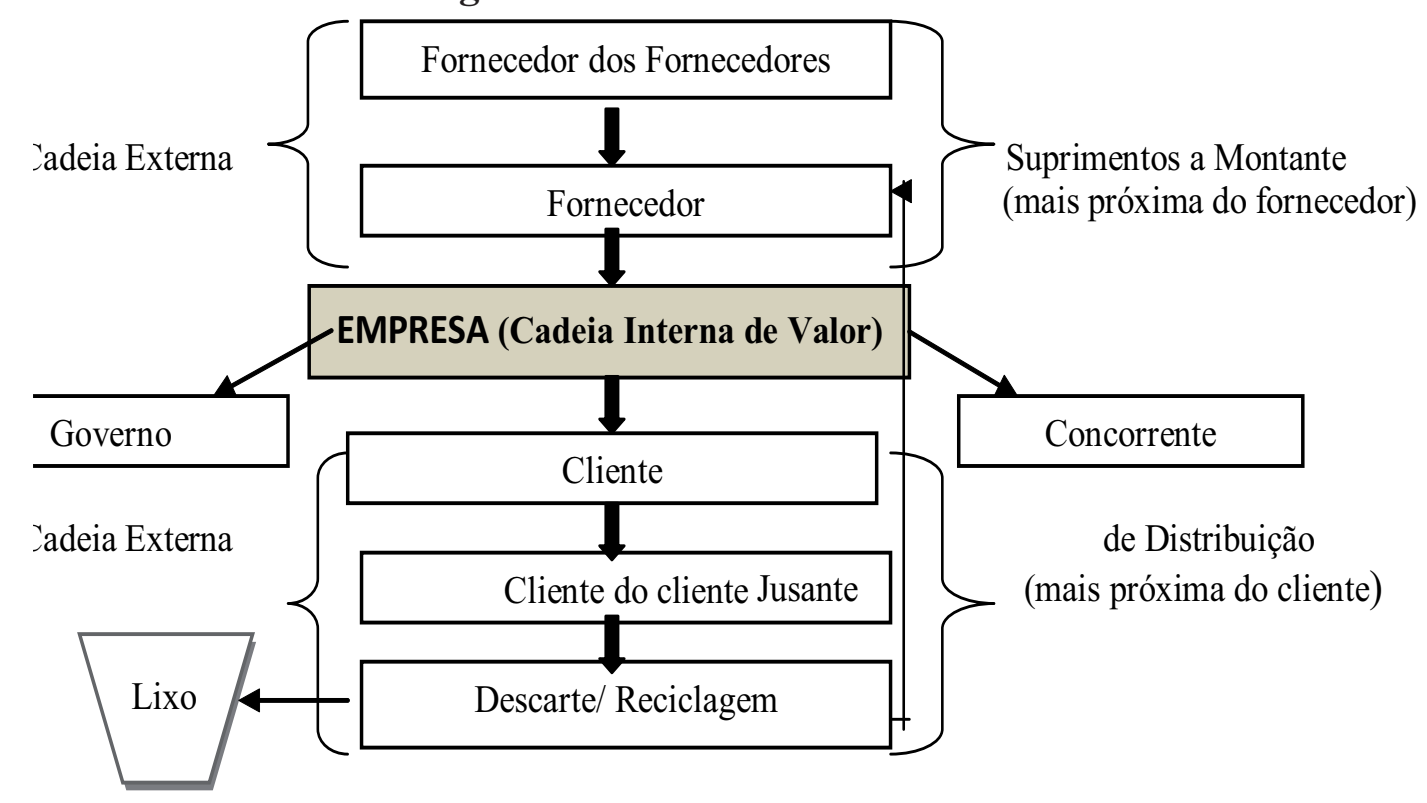

Fonte: Adaptado de Porter (1990).

Pode-se observar na Figura 2 os elos da cadeia de valor da empresa, ou seja, as ligações com clientes, fornecedores, concorrentes e até mesmo com o governo. Isso demonstra que as empresas exercem uma série de operações externas para manterem suas funções internas, sendo relevante manter uma interface com fornecedores e clientes. Os resultados dessas ligações (o lucro sem perder o foco na satisfação dos clientes) serão tão favoráveis quanto maior for a capacidade de utilização coordenada e otimizada dos recursos humanos, tecnológicos, financeiros e materiais disponíveis.

\subsection{Cadeia de Valor e Gestão Estratégica de Custos (GEC)}

Conforme apresentado por Bacic (1994), até meados da década de 1980, o campo da contabilidade de custos não tinha incorporado em seu escopo a dis- 
cussão das relações entre gestão de custos, estratégia e competitividade. Bartz, Staudt e Souza (2005) esclarecem que foi em decorrência da intensificação da concorrência que se teve a extensão do foco da gestão de custos de forma a tornála consistente com a elaboração e o desenvolvimento da estratégia competitiva empresarial. Shank e Govindarajan (1997) trouxeram o avanço na sistematização e detalhamento dessa nova abordagem de custos, época em que citaram a análise da cadeia de valor como um dos pilares de realização da GEC.

A GEC tem sido considerada como um importante instrumento para dar segurança na sustentação e condução dos negócios dada a sua capacidade informacional para direcionar a escolha, implementação e controle de estratégias competitivas. $\mathrm{O}$ enfoque de custos tem estado presente nas obras que tratam de estratégias e vantagens competitivas. As iniciativas de Porter (1986) no desenvolvimento das estratégias competitivas genéricas de liderança em custos e liderança em diferenciação, e suas relações com a análise da cadeia de valor, trouxeram mais destaque às relações entre esses elementos, corroborando pelo entendimento dado por Bacic (1994).

Para a eficácia nesse tipo de análise de custos, o foco são os conceitos estratégicos, especialmente sobre a cadeia de valor, o posicionamento estratégico e os direcionadores de custos. Isso porque, conforme enfatizado por Shank e Govindarajan (1997, p. 4), a gestão estratégica de custos é "uma análise de custos em que os elementos estratégicos tornam-se mais conscientes, explícitos e formais. Aqui, os dados de custos são usados para desenvolver estratégias superiores a fim de se obter uma vantagem competitiva". Logo, entende-se que o custo também é um instrumento a ser utilizado como ferramenta estratégica, num mercado altamente competitivo, onde diferenciais devem ser utilizados visando atingir os objetivos da empresa, baseado na satisfação dos clientes.

Para que as informações relacionadas a custo estejam disponíveis e ao alcance dos administradores de forma a atender as necessidades gerenciais, diversos sistemas de custeio foram desenvolvidos e aprimorados ao longo do tempo, destacando-se entre eles o custeio baseado em atividades - ABC. O uso das atividades como base de custeio e análise é um fator que aproxima o ABC da estrutura funcional da cadeia de valor. Isso está implícito no reconhecimento dado por Shank e Govindarajan (1997), os quais enfatizam a utilidade do ABC, destacando que ele permite o gerenciamento das atividades, podendo direcionar ações para eliminar aquelas que não agregam valor ao produto final.

A análise desses pronunciamentos conduz ao entendimento de que o sistema de custeio $\mathrm{ABC}$ é uma ferramenta que permite melhor visualização dos custos através da análise das atividades executadas dentro da empresa e suas respectivas relações com os objetos de custos. Nele, os custos tornam-se visíveis passando a serem alvos de programas de redução e de aperfeiçoamento de processos, au- 
xiliando, assim, as organizações a tornarem-se mais lucrativas e eficientes. Com seu poder de assinalar as causas que levam ao surgimento dos custos, o ABC permite aos gerentes uma atuação mais seletiva e eficaz sobre o comportamento dos custos da organização.

A necessidade de identificar os custos e suas causas, no processo da análise da cadeia de valor, implica na adoção do custeio $\mathrm{ABC}$, via identificação dos direcionadores de custos, o que possibilita melhor proceder à ligação das atividades aos produtos (HANSEN e MOWEN, 2001). A Figura 3 apresenta um breve fluxo dessa rotina de custos no âmbito da cadeia de valor.

\section{Figura 3 - A cadeia de Valor e o Método ABC}

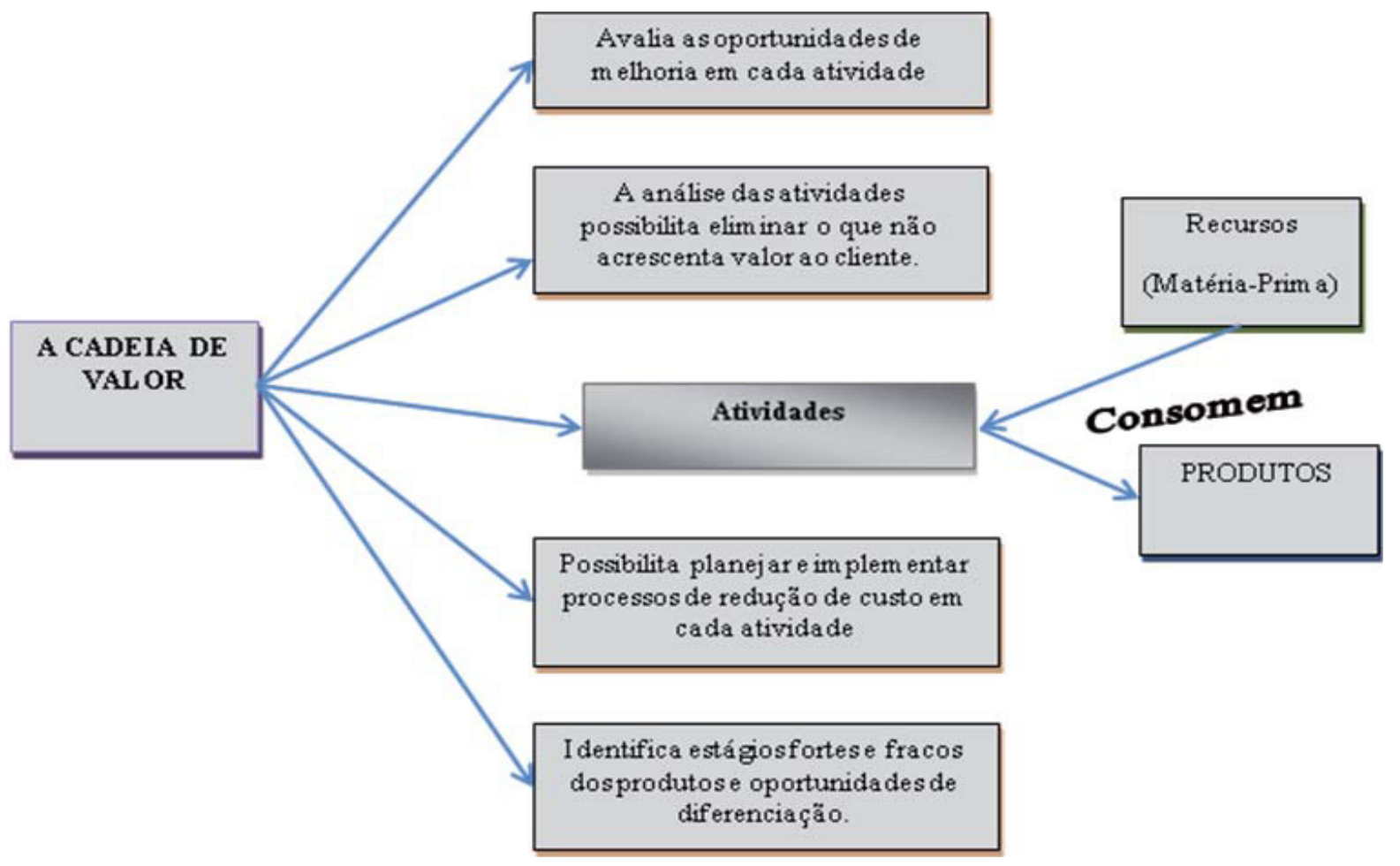

Fonte: Adaptado de Hansen e Mowen (2001).

Observa-se nessa Figura 3 que as atividades da cadeia consomem os recursos (matéria-prima, mão-de-obra e outros custos), e que os produtos e/ou serviços gerados consomem as atividades. A partir dessa relação é possível, via utilização dos direcionadores de custos, fazer-se uma análise ampla sobre as causas e usos dos recursos consumidos. $\mathrm{E}$ isso pode ser feito nas atividades relevantes que formam os principais elos (internos e externos) da cadeia de valor.

\subsection{Características Gerais da Cadeia de Valor na Construção Civil}

No Brasil, conforme enfatizam Teixeira e Carvalho (2005), a indústria da construção civil é tida como a atividade econômica de maior capacidade de 
geração de empregos e consumo de materiais. A partir daí a sustentabilidade desse setor é de grande relevância para a economia nacional, pois além da direta geração de empregos que provoca é uma atividade com grande potencial de expansão e impacto em outras atividades econômicas.

Blumenschein (2004) dá destaque à extensão da cadeia produtiva do setor, enfatizando que a sua composição envolve as cadeias de suprimento, de processo e auxiliares, compreendendo uma considerável absorção de recursos humanos, naturais e energéticos. Blumenschein acrescenta que além desses aspectos econômicos há também a sua abrangência social por suprir necessidades de moradia, saúde, educação, indústria e infra-estruturas urbanas.

A relevância do setor pode ser atestada pelos dados da CBIC (2008) referentes ao exercício de 2007. As 110 mil empresas do setor da construção ocuparam mais de 1,8 milhões de pessoas, tiveram gastos totais de $\mathrm{R} \$ 30,6$ bilhões com esse pessoal, $\mathrm{R} \$ 20,7$ bilhões dos quais na forma de salários, retiradas e outras remunerações, uma média mensal de 2,3 salários mínimos por funcionário. Os dados também revelam que as empresas realizaram obras e serviços no valor de $\mathrm{R} \$ 128,0$ bilhões, $\mathrm{R} \$ 51,3$ bilhões dos quais relacionados a construções para $\mathrm{o}$ setor público, equivalente a $40,1 \%$ do total. Na comparação com 2006, as construções cresceram $16,9 \%$.

Segundo o Relatório Anual de Informações Sociais (RAIS) do Ministério do Trabalho e Emprego (MTE) disponível no CBIC (2007) o setor é dividido em três subsetores: Edificações, Construção Pesada e Montagem Industrial. As edificações englobam obras habitacionais, comerciais, industriais, sociais e obras destinadas a atividades culturais, esportivas e de lazer; a construção pesada reúne obras em vias de transporte, de saneamento, de irrigação/drenagem, de geração e transmissão de energia elétrica e sistemas de comunicação; a montagem industrial, ou montagem eletromecânica, corresponde à etapa final dos projetos de implantação, ampliação ou reforma de unidades industriais. Ela é executada, normalmente, após a conclusão das obras de construção civil, ou pelo menos quando estas estiverem suficientemente avançadas. Ela compreende cinco atividades básicas: (a) montagem de estruturas metálicas; (b) montagem mecânica; (c) montagem de tubulações; (d) montagem elétrica; (e) montagem de instrumentação.

No ramo da construção civil identificam-se diversas atividades de diferentes naturezas, fazendo com que sua cadeia de valor seja extensa, algumas delas destacadas na sequência.

\section{a) Produção de Insumos}

1. Atividades das indústrias extrativistas - Extração de pedra, areia, argila;

2. Atividades de fabricação - de cimento, estruturas metálicas, válvulas, metalurgia e outros metais não ferrosos, esquadrias; 


\section{b) Comercialização de Insumos}

1. Empresas atacadistas e varejistas-de madeira, material de construção, ferramentas em geral.

\section{c) Atividades de Construção}

1. Preparação do terreno - terraplenagem;

2. Obras de engenharia civil - projetos de arquitetura e engenharia;

3. Obras para infra-estrutura, de instalação e de acabamento.

d) Atividades de Incorporação e Comercialização de Imóveis

1. Atividade de incorporação compra e venda de imóveis;

2. Corretagem e avaliação de imóveis;

3. Administração de locação de imóveis.

Conforme dados apresentados no Gráfico 1, relativos ao ano de 2008, a atividade Construção mostra participação equivalente a 59,9\% do total da cadeia produtiva setorial.

Gráfico 1 - Composição da Cadeia Produtiva da Construção Civil - 2008

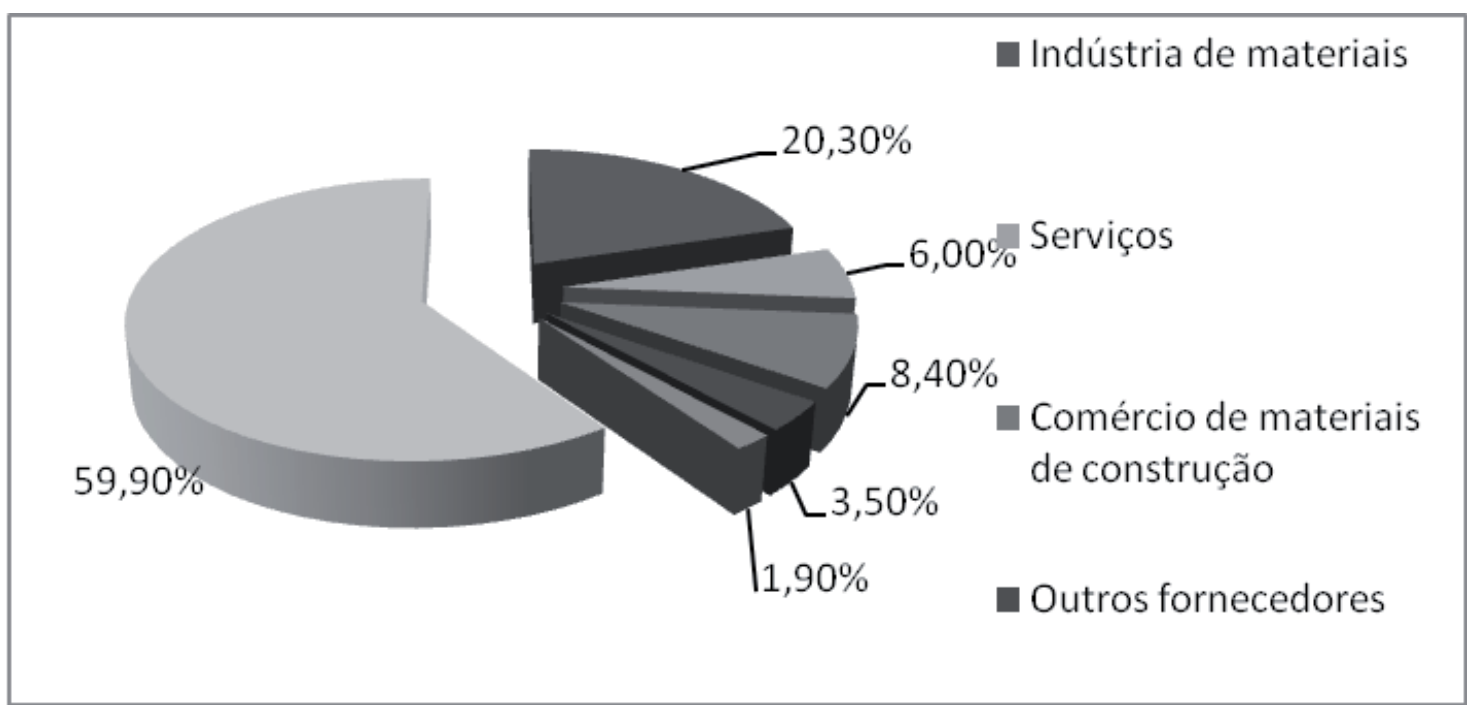

Fonte: CBIC (2008).

Quanto aos investimentos realizados pelas indústrias da construção civil no ano de 2007, ainda de acordo com dados de CBIC (2007), os valores brutos em ativos imobilizados totalizaram $\mathrm{R} \$ 5,1$ bilhões. A aquisição de máquinas e equipamentos foi o principal investimento e representou $44,2 \%$ do total. Em seguida surgem os gastos com meios de transporte, que corresponderam a 23,1\% do total investido, as compras de terrenos e as edificações com $21,3 \%$ finalizando com outras aquisições (móveis, microcomputadores e ferramentas), correspondente a $11,4 \%$ do total.

Para o Sindicato da Indústria da Construção do RS - SINDUSCON-RS (2009), a cadeia produtiva do setor pode ser definida como sendo o conjunto de todos os agentes do processo produtivo, desde a retirada da matéria-prima do solo até a entrega do produto final ao último consumidor. No caso da construção 
civil, consideram-se os fornecedores de areia, brita, pedra, argila, os fabricantes de cimento, aço, PVC, e alumínio como primeiros segmentos da cadeia, e os compradores dos imóveis como os clientes finais. Suas inter-relações são os elos da cadeia, ocasião em que esses fornecedores e clientes interagem e se interligam, formando a cadeia.

Nesse conceito, a cadeia produtiva abrange desde os agentes financiadores até o cliente final, integrando fabricantes de equipamentos, materiais e componentes, contratantes e investidores, órgãos públicos, imobiliárias, entidades técnicas, projetistas, incorporadoras, construtoras, empreiteiros, revendedores de materiais e o cliente final que adquire a obra pronta. Logo, pode-se identificar que a cadeia produtiva da construção civil não é somente o processo de produção do imóvel, limitado ao canteiro de obras e a edificação em si, mas sim a um conjunto de todos os setores envolvidos.

Segundo o SINDUSCON-MG (2009), para identificar sua importância na cadeia de valor do setor a empresa deve sempre analisar no mínimo, dois níveis que a antecedem e dois níveis que a sucedem. São os fornecedores de primeira e segunda camada e os consumidores de primeira e segunda camada. Desta forma, segundo o SINDUSCON-MG, a empresa pode identificar sua significância, de modo que ela tanto poderá avaliar e evitar a possibilidade de vir a ser excluída do processo, quanto lhe dará informação necessária para vislumbrar oportunidades de avançar para novos negócios, novos produtos e novos elos da cadeia dos quais ainda não participa.

Assim, o objetivo principal da análise de qualquer cadeia produtiva gira em torno do objetivo de identificar pontos fracos e fortes da cadeia, para que seja possível estudar formas de diferenciação, oportunidades de melhoria, meios de minimizar fraquezas e fazer uso das forças identificadas, de modo a alcançar o equilíbrio que permita o fortalecimento de toda a cadeia produtiva; e para que isso seja feito é necessária a identificação dos principais segmentos e elos que compõem a cadeia em análise.

\section{PROCEDIMENTOS METODOLÓGICOS}

\subsection{Classificação da Pesquisa}

A pesquisa, conforme delineamento apresentado por Mattar (2005) é classificada como exploratória, dado que tem por objetivo prover o pesquisador de maior conhecimento do tema ou problema de pesquisa em perspectiva. Também atende a classificação de uma pesquisa descritiva, pois o seu objetivo principal é a descrição de características de determinadas populações ou fenômenos estudados (GIL, 2002). 
Já quanto ao método de investigação a pesquisa classifica-se como qualitativa, a qual, conforme Richardson (1999) tem como uma das suas principais características a não utilização de instrumentos estatísticos para análise dos dados da pesquisa.

A pesquisa compreendeu a realização de estudos de casos em três empresas. A análise de casos múltiplos é importante porque, além de verificar similaridades ou diferenças entre as empresas estudadas, permite estabelecer que um estudo seja complementar ao outro, favorecendo uma melhor análise dos dados (YIN, 2005).

Seguindo orientação de Yin (2005), o estudo foi precedido da elaboração de um apropriado protocolo do estudo de caso. Tal protocolo, segundo Yin, contém os procedimentos, os instrumentos e as regras que devem ser seguidas na aplicação e no uso desses instrumentos. Constitui-se, portanto, numa tática para aumentar a fidedignidade dos dados da pesquisa e da continuidade do estudo até a sua conclusão e elaboração do respectivo relatório final.

\subsection{Caracterização das Unidades de Análise}

As unidades de análise utilizadas na pesquisa correspondem a empresas gaúchas que atuam no ramo da construção. Sabe-se que a atividade de construção civil é uma parte indispensável no desenvolvimento regional e nacional, gerando bens que produzem a infra-estrutura necessária para diversas atividades econômicas, além, é claro, de proporcionar bem-estar e qualidade de vida à sociedade (SEBRAE/CNI/IEL, 2000).

A construção civil é segmentada em dois grupos de atividades: As edificações (que englobam obras habitacionais, comerciais, industriais, obras sociais e obras destinadas a atividades culturais, esportivas e de lazer) e a construção pesada (compreendem as vias de transporte, obras de saneamento, de irrigação e drenagem, de geração e transmissão de energia elétrica, de sistemas de comunicação e de infra-estrutura de forma geral (TREVISAN CONSULTORES, 2007). Neste artigo estudam-se empresas que atuam tanto no grupo das edificações quanto no grupo da construção pesada.

O conceito utilizado para a escolha das três empresas participantes foi o de amostra não probabilística, definidas pelo critério de acessibilidade das empresas associadas ao SINDUSCON-RS Elas foram convidadas, via e-mail, e aceitaram participar da pesquisa.

\subsection{Procedimentos de Coleta de Dados}

A coleta de dados, realizada durante o terceiro trimestre de 2009, foi apli- 
cada por meio de entrevistas semi-estruturadas. A entrevista, segundo Yin (2005), é dedicada a abordar o entrevistado de forma a satisfazer às necessidades da linha de investigação. Dentre as principais vantagens das entrevistas, conforme apresentado por Lakatos e Marconi (1991), destaca-se que nela há maior flexibilidade para esclarecimento de dúvidas e compreensões entre os participantes, explicitar as questões de forma mais abrangente e segurança quanto a quem efetivamente participa do processo. Considera-se que esses aspectos destacados pelas autoras contribuem para melhor qualificação dos dados coletados.

Após a realização das três entrevistas, novos contados foram realizados com os entrevistados. O objetivo foi de equalizar questões e respostas a alguns aspectos específicos que surgiram isoladamente nas entrevistas durante a prima fase.

O roteiro utilizado na entrevista foi submetido ao um pré-teste, realizado com a participação de dois pesquisadores da área, além de um profissional não integrante de qualquer uma das três empresas pesquisadas. Em consequência desse procedimento foi possível reformatar algumas das 12 questões elaboradas, tornando-as mais claras e objetivas em relação ao objetivo do estudo. Duas questões adicionais resultaram de sugestões apresentadas por um dos pesquisadores consultados.

\section{APRESENTAÇÃO E ANÁLISE DOS CASOS ESTUDADOS}

A estrutura adotada para apresentação e análise dos casos estudados compreende três partes principais, a saber: (a) descrição geral de cada uma das empresas e dos profissionais pesquisados; (b) ações das empresas quanto às cadeias interna e externa de valor, às estratégias próprias adotadas na redução de custos e às parcerias realizadas com clientes, fornecedores e concorrentes; (c) análise comparativa sobre o posicionamento das três empresas.

A classificação do porte das empresas foi efetuada de acordo com o critério de receita operacional bruta anual, adotado pelo BNDES (2002). Assim, empresas de pequeno porte têm faturamento na faixa de $\mathrm{R} \$ 1,2$ a $\mathrm{R} \$ 10,5$ milhões, as médias empresas de $\mathrm{R} \$ 10,5$ a $\mathrm{R} \$ 60$ milhões e as grandes acima de $\mathrm{R} \$ 60$ milhões.

\subsection{Descrição Geral das Empresas Pesquisadas}

Como já destacado, o estudo foi desenvolvido com base em pesquisa realizada em três empresas gaúchas do ramo da construção civil, caracterizadas a seguir.

A primeira empresa pesquisada, aqui denominada EMPRESA ÉPSILON LTDA, foi constituída em 1980 e tem sua sede própria na Região do Vale do 
Rio dos Sinos, na cidade de São Leopoldo. Caracteriza-se por ser uma empresa de médio porte, com uma média de faturamento bruto anual na faixa de $\mathrm{R} \$ 30$ milhões e, de acordo com o entrevistado, conta com excelente credibilidade no mercado. É certificada pelo Programa Brasileiro de Qualidade e Produtividade do Habitat - PBQP-H, Nível A. A empresa atua no comércio de tubos, galerias e outros artefatos de cimento para obras de drenagem, saneamento e infra-estrutura; na prestação de serviços a empresa atua com terraplenagem, pavimentação e calçamento de ruas; no segmento das edificações, tem foco em obras industriais e comerciais área públicas e privadas, sendo que seus principais clientes são empresas de saneamento básico, prefeituras, madeireiras e demais construtoras. Nos últimos anos tem obtido êxito também no segmento da habitação econômica. Quando da pesquisa empregava aproximadamente 300 funcionários.

Foi entrevistado o diretor principal e também proprietário da empresa, com formação acadêmica de $3^{\circ}$ grau completo e 50 anos de idade.

A segunda entrevistada, identificada como EMPRESA LAMBDA LTDA, também estabelecida na cidade de São Leopoldo, está no mercado desde 1987 e atua no segmento da construção civil pesada, com a fabricação de tubos de concreto e outros artefatos de cimento. Entre os seus principais clientes, estão a Petrobrás, Copesul, Prefeituras e outras empresas privadas de pequeno e médio porte. Apresenta-se como uma empresa de porte médio, cujo faturamento bruto anual situa-se em R \$ 30 milhões. À época da pesquisa empregava cerca de 150 funcionários.

Foi entrevistado um dos proprietários da empresa, com 40 anos de idade e primeiro grau incompleto. A empresa é do tipo industrial, comercial e prestadora de serviços. Tem uma estrutura de médio porte e faz parte de um grupo de outras três empresas de segmentos interligados, cuja atuação concentra-se nas atividades de urbanização, construção e incorporação de imóveis.

Por fim a terceira pesquisada, identificada neste estudo como EMPRESA ÔMICRON LTDA, também está estabelecida na Região do Vale do Rio dos Sinos, cidade de Novo Hamburgo. Constituída em agosto de 2001, atua no ramo de edificações mediante a prestação de serviços e fornecimento de material. Sua clientela é formada por empresas privadas, não realizando serviços para órgãos ou empresas públicas. É uma empresa de pequeno porte, com faturamento bruto anual na faixa de R 55 milhões e com uma filial na cidade de São Paulo-SP. Na época da pesquisa, empregava em torno de 15 funcionários, trabalhando também com mão de obra terceirizada, o que representa um adicional de cerca de 40 funcionários.

Foi entrevistado o gerente geral da unidade de Novo Hamburgo, pouco acima dos 30 anos de idade e com curso superior em andamento na área da Engenharia. 


\subsection{Análise dos Dados}

\subsubsection{Empresa Épsilon}

\section{a) Quanto à cadeia interna de valor}

Quando usada a terminologia técnica e academicamente apropriada de "análise da cadeia interna de valor" o entrevistado manifestou desconhecer o assunto, porém, após um breve esclarecimento adicional, ficou claro que na prática o conceito tem sido sim aplicado na empresa.

Conforme informado, a empresa conhece e faz análise de todas as atividades internas da organização, principalmente no que diz respeito à execução das obras. Esta análise é realizada, segundo o gestor, desde a entrada dos materiais até sua distribuição entre as obras. O processo continua até a assistência e manutenção das obras depois de finalizadas e entregues aos clientes.

Além desse tratamento específico quanto às obras também há uma detalhada verificação de cada processo desenvolvido nos setores de apoio da empresa, começando pelo setor de compras, passando pela área de RH e demais áreas da infra-estrutura geral da empresa. O entrevistado acrescentou que apesar de todos esses esforços somente no setor de execução física das obras tem se conseguido manter o custo próximo do desejado, o que não vem ocorrendo nas áreas de suporte onde os custos ainda estão elevados.

A análise da cadeia interna de valor é feita com mais detalhamento naquelas atividades onde os custos são mais representativos e que possam não estar agregam valor ao cliente. Com base nestas informações a empresa busca alternativas de redução dos custos sem que isso implique em diminuir a qualidade do material aplicado nas obras e à qualidade do serviço prestado. Conforme acrescentado pelo entrevistado, esse procedimento decorre das principais políticas da empresa em relação ao mercado direcionadas a oferecer produtos e serviços com alto valor agregado.

\section{b) Quanto à cadeia externa de valor}

Também com referência ao conceito da cadeia externa de valor notou-se a falta de conhecimento pelo entrevistado, o que, novamente, tornou necessária a exposição das principais características da técnica. A partir daí o entrevistado se identificou facilmente com o novo tema, conseguindo explicar as relações da empresa no âmbito do ambiente onde está inserida, o que inclui seus elos com clientes, fornecedores, governo e até mesmo concorrentes. Segundo ele, a organização consegue se identificar na cadeia de valor do segmento da construção civil, onde atua adquirindo e comercializando o material necessário para a execução 
A empresa se considera um elo forte da cadeia, dado o diferencial da garantia oferecida aos serviços prestados e à qualidade do material utilizado. A empresa não pretende ampliar sua posição na cadeia de valor do segmento, o que significa não criar novos serviços ou expandir para outros segmentos desse mercado. Assim, pretende manter seu foco concentrado nas atividades de obras públicas, obras imobiliárias e obras de clientes privados.

\section{c) Quanto a estratégias próprias adotadas para redução de custos}

O entrevistado enfatizou o reconhecimento que há na empresa quanto à necessidade de contínua busca pela eficiência operacional, entendendo que isso é um pré-requisito à continuidade dos negócios.

Para tornar essa política uma prática efetiva a empresa direciona esforços e estratégias para controlar e reduzir custos. Algumas dessas estratégias são destacadas a seguir: (a) investimento em tecnologia, para mecanização cada vez maior nas obras, eliminando assim o excesso de mão de obra, encargos trabalhistas, entre outros determinantes de custos; (b) aquisição de materiais e serviços que agreguem valor ao seu produto, mesmo que a valores comparativamente mais altos, o que sinaliza uma busca pela diferenciação; (c) padronização e aperfeiçoamento de projetos, o que faz com que a partir da elaboração do segundo projeto o custo seja inferior; (d) investimentos em qualificação e retenção de mão-de-obra, visando proporcionar serviço de maior qualidade e valor agregado; (e) rigoroso controle de todo material utilizado nas obras, ensejando na maior eficiência no processo de logística interna e externa.

\section{d) Quanto a parcerias com clientes, fornecedores ou concorrentes como estratégia para redução de custos}

O entrevistado revela que a empresa possui sim parcerias estratégicas, mas somente com fornecedores. Com clientes e concorrentes ela ainda não possui nenhum tipo de parceria, embora não descarte a possibilidade de vir a ocorrer.

A parceria com fornecedores ocorre no desenvolvimento de novos produtos, tais como melhora nas especificações necessárias aos materiais utilizados nas edificações. Essa parceria também é realizada no aperfeiçoamento de produtos já existentes, como é o caso das lajes: elas vinham soltas do fornecedor obrigando uma atividade de montagem na empresa - após uma atividade conjunta o produto foi redesenhado e hoje as lajes são montadas e entregues pelo fornecedor dentro da obra, o que possibilitou eliminar os custos de montagem na empresa (realizada pelo fornecedor a um custo mais baixo) e o custo de armazenagem incidente até o momento do uso efetivo.

Outra parceria que merece destaque é a realizada com o fornecedor de argamassa, o qual desenvolveu um produto especialmente para aplicação nas obras 
da empresa, que agrega valor no produto final entregue ao cliente visto proporcionar um acabamento diferenciado. Também foi citada a parceria realizada com empresas de engenharia o que viabilizou o desenvolvimento de projeto-padrão para as edificações, reduzindo consideravelmente os custos dessa atividade

\subsubsection{Empresa Lambda}

\section{a) Quanto à cadeia interna de valor}

A exemplo, do ocorrido com o representante da empresa Épsilon também nesta segunda empresa o entrevistado desconhecia esse termo técnico como forma de analisar as atividades internas do processo operacional da empresa.

Esclarecida a questão o diretor entrevistado revelou que as atividades internas da organização são sim analisadas periodicamente. É essa forma de gerenciamento constante de cada atividade dentro da empresa é que permite aos gestores tomar decisões visando a sua maior eficiência e produtividade. Além disso, também direciona decisões quanto à busca de soluções externas à empresa, o que se realiza por meio de parcerias.

Algumas das atividades, em virtude da sua relevância em fatores de competitividade, recebem maior atenção nesse processo de gestão da cadeia interna de valor. São elas: (a) desenvolvimento de tecnologia - a empresa possui um laboratório interno próprio, onde são realizados todos os tipos de testes com cada produto desenvolvido, o qual já sai da fábrica com todas as especificações necessárias para participar de qualquer tipo de licitação pública; (b) no setor de compras - as emissões das ordens de compra são feitas sob rigoroso controle das matérias-primas adquiridas; o cimento, por exemplo, somente é adquirido de uma indústria paranaense por ser a única que utiliza um componente especial anti-corrosivo. Isso é feito mesmo com o cimento custando aproximadamente $17 \%$ mais caro, tendo em vista os ganhos oferecidos pelo excelente e diferenciado acabamento do produto; (c) gerência de recursos humanos - a empresa investe em cursos de qualificação e treinamento da mão de obra, buscando desenvolver e reter colaboradores capacitados, evitando maiores custos de contratação no futuro.

\section{b) Quanto à cadeia externa de valor}

Também aqui foi necessário fazer uma pequena introdução do conceito de cadeia externa de valor. Exposto o conceito, o entrevistado confirmou que faz essa análise, que conhece a participação e relacionamentos com as demais empresas de segmento, bem como procura explorar as potenciais ligações com clientes, fornecedores, governo e até mesmo com concorrentes.

A direção da empresa sabe exatamente qual é o seu principal concorrente, como ele se insere e interfere na cadeia de valor do segmento. Foi uma atuação 
mais proativa na análise em outros segmentos da cadeia produtiva que possibilitou à empresa ampliar sua atuação na cadeia produtiva de tubulações de líquidos cloacais domiciliários e industriais (esgoto cloacal é aquele formado pela água escoada de tanques de roupa, pias de cozinha, banheiros e descargas sanitárias).

A organização considera-se localizada num dos elos fortes da cadeia de valor do seu segmento, tanto por atuar nos três ramos da atividade (industrial, comercial e prestação de serviços) como por produzir grande parte da matéria prima necessária à fabricação de seu produto (indício de verticalização) o que contribui para uma redução de custos de até 40\% no produto final, tornando-a altamente competitiva no mercado. Esse último esclarecimento do entrevistado indica a opção pela estratégia de maior verticalização da empresa.

\section{c) Quanto a estratégias próprias adotadas para redução de custos}

O gestor entrevistado relata que essa análise do ambiente externo, via cadeia de valor, tem contribuído para que a empresa tome novas decisões de investimentos, principalmente em tecnologia. Tais investimentos têm possibilitado a criação de novos produtos, além da produção em maior escala, com mais qualidade e menor custo.

Tem-se também a criação de novas unidades de negócios, objetivando o desenvolvimento de produtos ecologicamente corretos, com tecnologia importada e sem similar no Brasil, reduzindo assim o número de concorrentes potenciais. Segundo o entrevistado esse é um diferencial no segmento, o que motiva a busca cada vez maior de expansão dos negócios, projetando a empresa e para outras regiões do país, inserindo-a na cadeia de valor de outros estados, como Santa Catarina e Paraná.

Outra estratégia adotada refere-se à melhor qualificação do produto comercializado com órgãos públicos. Para isso, a empresa tem contrato com a Cientec (uma fundação do governo do RS voltada para a ciência e tecnologia) a qual atua diretamente nos laboratórios da empresa com a finalidade de assegurar que os lotes de produtos já saiam da empresa aprovados. Este processo reduz o custo logístico causado por uma provável reprovação da amostra analisada além de prejudicar a empresa em participar de futuras licitações.

Além dessas ações específicas a empresa mantém a política de incrementar a qualificação de mão-de-obra, realizada por meio de um programa de treinamento e reciclagem contínuos.

\section{d) Quanto a parcerias com clientes, fornecedores ou concorrentes como estratégia para redução de custos}

De acordo com informações do entrevistado, a empresa possui sim algumas parcerias com fornecedores e concorrentes na busca pela redução de custos 
e maior valor agregado ao produto vendido. $\mathrm{O}$ entrevistado acrescentou que essa postura é reflexo do reconhecimento de que nem sempre a empresa detém todas as habilidades e recursos físicos para assegurar a continuidade sustentável das atividades.

Uma dessas parcerias com fornecedores acabou por redundar na realização de um investimento para aquisição de $50 \%$ de um fornecedor de areia, dada a necessidade da empresa em interferir no processo de granulação da areia com o objetivo de conseguir se abastecer de matéria-prima com a granulação exata que precisava. A partir dessa aquisição parcial do fornecedor a empresa investiu em tecnologia e resolveu o problema de abastecimento. $\mathrm{O}$ entrevistado concluiu informando que inicialmente o investimento foi significativo, mas que o maior valor agregado ao produto viabilizou o retorno desejado com o investimento. Além desse aspecto econômico a ação também serviu para criar uma barreira de entrada a novos concorrentes.

Outra importante parceria realizada pela empresa ocorreu na forma de uma ação conjunta desenvolvida com três grandes concorrentes, um de São Paulo, um do Rio de Janeiro e outro de Minas Gerais. A não inserção dos concorrentes nos mercados de atuação dos demais viabilizou a realização da parceria.

A referida parceria ocorreu na contratação de uma empresa encarregada de desenvolver uma máquina específica para a fabricação de tubos e artefatos de cimento. Se a empresa fabricante fosse desenvolver esta máquina somente para a empresa pesquisada, custaria algo em torno de $\mathrm{R} \$ 402$ mil. No entanto, com essa parceria estratégica realizada com mais três empresas, suas concorrentes que também tinham interesse em adquirir a máquina, reduziu-se o investimento em $22 \%$, com o valor da máquina sendo agora fixado em $\mathrm{R} \$ 330$ mil. Isso possibilitou um ganho expressivo para cada empresa da parceria na aquisição de sua máquina, bem como para o fornecedor que acabou por negociar três unidades ao invés de, talvez, nenhuma.

\subsubsection{Empresa Ômicron}

\section{a) Quanto à cadeia interna de valor}

Repetiu-se nessa terceira empresa aquela mesma situação das duas anteriores a respeito dos entrevistados desconhecerem a técnica da cadeia de valor. Isso foi particularmente inesperado nesta empresa, pois contrariamente às outras nessa o entrevistado está em fase de conclusão do curso universitário de engenharia no qual, esperava-se o assunto fosse abordado.

Após os esclarecimentos sobre a cadeia de valor o entrevistado informou que na prática desenvolve alguns estudos sob esse enfoque. Acrescentou que a análise é feita principalmente no que diz respeito às obras. Assim, para cada 
obra orçada é feito um cronograma nos mínimos detalhes, envolvendo todas as atividades necessárias para a execução do serviço, verificando-se o custo de cada uma delas, base para formar o preço ao cliente.

Quanto aos projetos, há uma empresa engenharia contratada sob o formato de uma terceirização, pelo qual há uma prestação de serviços exclusivos. Dada a explícita dependência contratual, a empresa contratada é considerada como parte dos processos internos da empresa entrevistada, o que a configura como um elo da cadeia interna de valor. Essa ação é considerada relevante, pois por meio dela é possível desenvolver projetos personalizados em relação às necessidades do cliente, o que é considerado um diferencial em relação ao concorrente que trabalha somente com projetos padronizados.

Conforme informado pelo entrevistado, foi a análise da cadeia interna de valor que indicou à empresa a viabilidade de terceirizar a contabilidade enquanto uma das atividades do setor de apoio. O custo de manter essa atividade, segundo o entrevistado, mostrou-se elevado. A atividade de contabilidade compreendia os departamentos de contabilidade, pessoal e escrita fiscal dentro da empresa. Nota-se que o departamento de pessoal também era considerado na empresa como parte da contabilidade, agora terceirizada.

\section{b) Quanto à cadeia externa de valor}

Conforme informado pelo entrevistado, a análise da cadeia externa de valor é feita apenas de forma superficial. A empresa não sabe identificar exatamente se faz parte de um elo forte ou fraco na construção da cadeia de valor. A suposição que há na empresa é que ela não seja um elo de grande influência em relação aos demais visto que apenas presta o serviço das edificações fornecendo material.

Para o entrevistado a empresa tem muita dependência em relação aos seus fornecedores para processar o fechamento do preço final aos clientes (pouco poder de negociação); na prática ela precisa que o fornecedor garanta o preço durante o contrato da obra, o que nem sempre ocorre.

$\mathrm{O}$ entrevistado revelou que a empresa não planeja atuar em novos segmentos de mercado, porque no momento acredita estar sem recursos para um maior crescimento. O planejamento privilegia continuar atuando no ramo das edificações, de forma bastante parcial. Também não há planos para trabalhar com licitações de fornecimentos para órgãos públicos. Além da falta de recursos também há a percepção de que os resultados atuais têm atendido as perspectivas dos gestores.

\section{c) Quanto a estratégias próprias adotadas para redução de custos}

A empresa tem direcionado algumas ações para atender o objetivo de redução de custos e manter-se competitiva no mercado. Segundo o entrevistado 
as principais ações são as seguintes:

(1) Trabalhar junto com empresas de engenharia no desenvolvimento de projetos, pensando em cada uma das atividades necessárias para montar a edificação - trata-se de uma maneira de reduzir os custos ao máximo, sem afetar a qualidade da obra, a fim de assegurar o alcance da rentabilidade desejada;

(2) Investir em tecnologias nacionais, adquiridas sempre com o uso de capital próprio, evitando os encargos financeiros dos financiamentos - os objetivos com tais tecnologias é reduzir o custo e melhorar a qualidade dos serviços;

(3) Continuar a desenvolver formas mais apropriadas de calcular preços no fechamento do projeto a fim de evitar desvios acentuados nos custos e comprometimento das margens de lucro - até o presente a empresa tem conseguido alcançar seus objetivos dado que os custos têm variado no máximo em torno de $2 \%$ a $3 \%$; mesmo assim, a cada novo projeto faz-se uma rigorosa atualização das estimativas dos custos.

\section{d) Quanto a parcerias com clientes, fornecedores ou concorrentes como estratégia para redução de custos}

O entrevistado informou que a empresa, na busca de redução de custos, tem sim desenvolvido algumas parcerias desenvolvidas especificamente com fornecedores e clientes.

Uma das parcerias mais importantes, considerada pelo entrevistado como crucial, é a realizada no momento do orçamento da obra, quando a empresa se reúne com seus fornecedores para garantir o preço do material fornecido até o final da obra, fator determinante na formação do custo e margem de lucro da empresa a ser repassada ao cliente. Isso tem sido relevante dado que o tempo de realização de uma obra pode variar muito, indo de um a cinco anos. Logo, se o fornecedor não garantir o preço a empresa terá de reajustar o orçamento constantemente, o que geralmente encontra resistências dos clientes. Apesar do baixo poder de negociação junto aos fornecedores, a empresa tem procurado realizar as melhores negociações possíveis.

Outra forma de atuação em conjunto é o relacionamento mantido com os clientes. Antes de fechar contratualmente o orçamento a empresa se reúne com o cliente e analisa de forma compartilhada todas as variáveis do projeto, ou seja, todas as atividades que terão de ser executadas naquele empreendimento. Além das questões tributárias negocia-se a possibilidade do cliente se comprometer com o fornecimento do material, situação em que o faturamento do projeto restringe-se ao fornecimento de serviços de projeto, execução e administração da obra. Quando o serviço é prestado para grandes empresas há predominância dos contratos limitarem-se à prestação de serviços, tendo em vista o poder de 
negociação que elas têm. Segundo o entrevistado, essa forma mais transparente de negociar tem possibilitado que alguns contratos aparentemente inviáveis sejam concretizados.

Até o momento da realização desta pesquisa o representante da empresa participante informou que ela nunca teve qualquer experiência de ação conjunta com concorrentes. Apesar de entender que há diversas barreiras para que isso ocorra, ele não descarta totalmente a sua possível realização no futuro. Ele acrescentou que o segmento é ainda muito fechado e resistente a esses avanços.

\subsection{Análise Comparativa das Empresas}

A análise comparativa do posicionamento das três empresas pesquisadas sobre ações que envolvem a análise da cadeia de valor, no contexto da gestão estratégica de custos, revela diversos aspectos comuns a todas elas.

A primeira corresponde ao desconhecimento dos entrevistados quanto ao conceito que é dado a cadeia de valore pela literatura da área. Se isso pode ser uma consequência da fraca formação acadêmica dos dois primeiros entrevistados (empresas Épsilon e Lambda) - respectivamente terceiro grau completo e primeiro grau incompleto - o mesmo não pode ser argumentado pelo terceiro entrevistado (empresa Ômicron) dada a sua formação superior em andamento, na área de engenharia.

Outra característica comum é que apesar de desconhecerem o conceito, a prática da análise e uso da cadeia de valor, interna e externa, tem sido adotada pelas empresas, com maior ou menor amplitude dependendo de cada empresa. Verificou-se que nas duas primeiras empresas, de porte médio, o uso se apresenta mais intensivo do que na terceira empresa, a menor entre elas (pequeno porte).

Apesar dos usos e aplicações retratados pelos entrevistados, observa-se que isso ocorre com significativa superficialidade. Em nenhum momento os entrevistados fizeram referência à mensuração das contribuições de cada fase dos elos da cadeia interna e tampouco da cadeia do segmento, conforme sugerido por Rocha e Borinelli (2007). Também foi possível identificar que a figura de elos e atividades ainda está muito interpretada na tradicional figura dos departamentos.

Acredita-se que essa superficialidade na análise da representatividade dos elos da cadeia e da empresa em relação à cadeia total provoca a não evidenciação de informações relevantes para direcionar ações de maior profundidade e abrangência na gestão dos negócios. A principal perda está na não identificação de oportunidades de melhora no desempenho das atividades e da própria inserção da empresa em outros elos da cadeia.

Um dos reflexos dessa superficialidade está refletida na baixa intensidade das parcerias realizadas com fornecedores e clientes, com predominância dos 
primeiros. Maior ausência ainda ocorre na exploração de possíveis parcerias com concorrentes.

Apesar do maior detalhamento apresentado nas aplicações realizadas pelas duas primeiras empresas é possível verificar que em todas elas há ainda um longo caminho a ser percorrido para explorar de forma mais proveitosa os potenciais benefícios da análise da cadeia de valor.

\section{Conclusões}

A partir da premissa de que a gestão estratégica de custos na cadeia de valor é um instrumento relevante para o estabelecimento e manutenção de diferenciais competitivos em relação à concorrência ( PORTER, 1989; SHANK; GOVINDARAJAN, 1997), o objetivo geral da pesquisa foi identificar de que forma os procedimentos de análise da cadeia de valor são adotado por empresas construtoras gauchas.

Os principais resultados da pesquisa sinalizam que o termo cadeia de valor é desconhecido pelos gestores das três empresas. Entretanto, no decorrer da pesquisa identificou-se que, na prática, ações com essa natureza são realizadas, apesar de não com a profundidade que a literatura recomenda.

As três empresas conhecem seu posicionamento na cadeia do segmento, um requisito essencial segundo Porter (1990). Duas delas (Épsilon e Lambda) se consideram como um elo forte. A outra empresa (Ômicron) reconhece sua fraqueza na cadeia. Consideradas algumas diferenciações, todas as empresas realizam parcerias com outros elos da cadeia - clientes e fornecedores. As empresas Épsilon e Lambda declaram parcerias e ações conjuntas inclusive com clientes. No geral, essas ações tem propiciado consideráveis reduções de custos e reconfiguração de negócios (aquisição de fornecedores, estrutura com maior verticalização, aquisições conjuntas). Mesmo com as limitações dos procedimentos adotados, as empresas, principalmente Épsilon e Lambda, utilizam procedimentos de relacionamento com outros agentes da cadeia de valor em que atuam, conforme apregoam Faria e Costa (2005) e Rocha e Borinelli (2007).

É explícita a manifestação das empresas quanto às preocupações com a eficiência das operações e redução de custos. Entretanto, nenhuma delas adota os procedimentos de mensuração destacados pela literatura. De fato, adoção do custeio ABC, mensuração de receitas, custos e ativos de atividades e elos da cadeia, simulação de possíveis reconfigurações, entre outros, não integram a realidade das empresas pesquisadas. Tal realidade distancia-se muito dos desenvolvimentos teóricos atuais, conforme enfatizam, por exemplo, Rocha (1999), Garrison e Noreen (2000) e Hansen e Mowen (2001).

Em termos de perspectivas, informações específicas sobre o plano de avan- 
çar a gestão com foco na cadeia de valor estiveram mais presentes nas empresas Épsilon e Lambda. O mesmo não foi identificado na Ômicron, auto reconhecida como um elo fraco da cadeia.

Enfim, os dados e informações apresentados no estudo sinalizam a ainda ação com foco individualizado, principalmente pela exploração do poder econômico dos fornecedores nos momentos de negociações de preços, prazos e outros atributos exigidos na prestação de serviços. Apesar de constatar alguns avanços, parece claro que há ainda uma distância acentuada em relação aos procedimentos apresentados pela literatura que trata do tema.

Considerando a diversidade de segmentos que constituem a indústria da construção civil, a significativa importância do posicionamento estratégico para o setor, bem como da gestão de custos, sugere-se o desenvolvimento de novos estudos nesse segmento de negócios.

Especificamente, recomenda-se estudos voltados para a cadeia de valor e a gestão estratégica de custos dos grandes projetos na construção civil pesada, ou mesmo nas empresas construtoras de imóveis residenciais, tema com pouca literatura publicada, apesar da destacada representatividade desses segmentos no desenvolvimento sustentável da economia brasileira.

\section{Referências}

BACIC, Miguel Juan. Escopo da Gestão Estratégica de Custos em Face das Noções de Competitividade e de Estratégia Empresarial. In: Congresso de Gestão Estratégica de Custos, I, São Leopoldo, 1994. Anais ... São Leopoldo, Unisinos, p.295-304, Nov/1994.

BANCO NACIONAL DE DESENVOLVIMENTO ECONÔMICO E SOCIALBNDES. Carta Circular 64/2002 referente a Porte de Empresas. 2002. Disponível em: http://www.bndes.gov.br/SiteBNDES/bndes/bndes_pt/Navegacao_Suplementar/Perfil/Grande_Empresa/porte.html. Acesso em: $10 \mathrm{dez} 2009$.

BARTZ, Daniel; STAUDT, Tarcísio; SOUZA, Marcos A. Gestão estratégica de custos: uso da engenharia reversa na análise dos custos de concorrentes. BASE, v.2, n.3, p.167-175, set/dez 2005.

BLUMENSCHEIN, Raquel Naves. A sustentabilidade na cadeia produtiva da indústria da construção. Tese (Doutorado) - Centro de Desenvolvimento Sustentável, Universidade de Brasília - UnB, Brasília, 2004.

CÂMARA BRASILEIRA DA INDÚSTRIA DA CONSTRUÇÃO CIVIL - CBIC. Banco de dados. 2007. Disponível em: <www.cbic.org.Brasil/cadprod/frm_cad- 
prod.htm>. Acesso em: 13 ago 2009.

CÂMARA BRASILEIRA DA INDÚSTRIA DA CONSTRUÇÃO CIVIL - CBIC. Banco de dados. 2008. Disponível em: <www.cbic.org.Brasil/cadprod/frm_cadprod.htm>. Acesso em: 26 fev. 2010.

CARVALHO, Mary; LAURINDO, Fernando. Estratégia para a Competitividade. São Paulo: Futura, 2003.

CINQUINI, L.; TENUCCI, A. Strategic management accounting exploring links with strategy. 2006. Disponível em: www.unisanet.unisa.edu.au/Resources/.../ Cinquini\%20\&\%20Tenucci.pdf. Acesso em: 30 set. 2009.

FARIA, Ana; COSTA, Maria. Gestão de custos logísticos. São Paulo: Atlas, 2005.

FRANCO, Hilário. A contabilidade na era da globalização. São Paulo: Atlas, 1999.

GARRISON, Ray H.; NOREEN. Eric W. Contabilidade Gerencial. Rio de Janeiro. LTC. 2000.

GIL, Antonio Carlos. Como elaborar projetos de pesquisa. 4 a Ed. São Paulo: Atlas, 2002.

GOMES, Josir S. Tópicos contemporâneos em contabilidade. CFC, RBC, n. 91, p. 79, 1995

HANSEN, Don R., MOWEN, Maryane M. Gestão de Custos, "Contabilidade e Controle". São Paulo: Pioneira Thomson Learning, 2001.

IUDÍCIBUS, Sérgio. A gestão estratégica de custos e sua interface com a contabilidade gerencial e teoria da contabilidade. CFC, RBC, n. 100, p. 30-31, jul/ ago 1996.

KAPLAN, R. S.; ANDERSON, S. Custeio baseado em atividade e tempo. Rio de Janeiro: Elsevier, 2007.

LAKATOS, Eva Maria; MARCONI, Marina de Andrade. Fundamentos de metodologia científica. $3^{\text {a }}$ Ed. São Paulo: Atlas, 1991.

MATTAR, Fauze N. Pesquisa de Marketing: Metodologia, Planejamento. $6{ }^{\text {a Ed. }}$ São Paulo: Atlas, 2005. 
MORELLI, Beata; WIBERG, Carl-Joachim. The standard costing system at SKF. Accounting \& Finance Master Thesis Göteborg University, 2002. Disponível em: http://www.handels.gu.se:81/epc/archive/00002757/01/gbs_thesis_2002_48.pdf. Acesso em: 05 nov. 2009.

PORTER, Michael E.: Estratégia Competitiva: Técnicas para Análise de Indústrias e da Concorrência. Rio de Janeiro: Campus, 1986.

PORTER, Michael E. Vantagem Competitiva: Criando e sustentando um desempenho superior. 13 ed. Rio de Janeiro: Campus, 1989.

PORTER, Michael E. Vantagem Competitiva, Criando e Sustentando um Desempenho Superior. Rio de Janeiro: Campus, 1990.

QUESADO, P.R.; RODRIGUES, L.L. A gestão estratégica de custos em grandes empresas portuguesas. Revista Iberoamericana de Contabilidad de Gestión, v.5, n.10, p.121-143, 2007.

RATTRAY, C.J.; LORD, B.R.; SHANAHAN, Y.P. Target costing in New Zealand manufacturing firms. Pacific Accounting Review, v.19, n.1, p.68-83, 2007.

RICHARDSON, Roberto. J. Pesquisa Social: Métodos e Técnicas. $3^{a}$ ed. São Paulo: Atlas, 1999.

ROCHA, Wellington. Contribuição ao Estudo de um Modelo Conceitual de Sistemas de Informação de Gestão Estratégica. Tese (Doutorado em Controladoria) - Faculdade de Economia, Administração e Contabilidade, Universidade de São Paulo, São Paulo - SP. 1999.

ROCHA, Wellington; BORINELLI, Márcio Luiz. Análise Estratégica da Cadeia de Valor: um estudo exploratório do segmento indústria-varejo. Revista Contemporânea de Contabilidade, v. 1, n. 7, p.145-165, jan./jun. 2007.

SEBRAE/CNI/IEL. PROJETO TECNOLOGIA DA PRODUTIVIDADE - Série Qualidade dos Materiais e Componentes na Construção Civil no Estado de São Paulo. Brasília-DF, 2000.

SHANK, John K.; GOVINDARAJAN, Vijay. A Revolução dos Custos. $6^{\mathrm{a}}$ Ed. Rio de Janeiro: Campus, 1997.

SILVA, Christian Luiz; KOPITTKE, Bruno Hartmut. Simulações e Cenários a partir da Cadeia de Valor: Uma Aplicação na Indústria de Celulose. Rev. FAE, Curitiba, v.5, n.1, p.43-59, jan./abr. 2002. 
SINDICATO DA INDÚSTRIA DA CONSTRUÇÃO - SINDUSCON - MG. Disponível em: <http://www.sinduscon-mg.org.br/pbqp-h/cadeia.html>. Acesso em: 05 jul. 2009.

SINDICATO DA INDÚSTRIA DA CONSTRUÇÃO - SINDUSCON - RS. Disponível em: <http://www.sinduscon-rs.org.br/pbqp-h/cadeia.html>. Acesso em: 06 jul. 2009.

SULAIMAN, M., AHMAD, N.N.N.; ALWI, N. M. Management accounting practices in selected Asian countries. Managerial Auditing Journal, v. 19, n.4, p.493-508, 2004.

SULAIMAN, M., AHMAD, N.N.N.; ALWI, N. M. Is standard costing obsolete? Empirical evidence from Malaysia. Managerial Auditing Journal, v. 20 n.2, p.109-124, 2005.

TAVARES, Mauro Calixta. Gestão estratégica. São Paulo: Atlas, 2000.

TEIXEIRA, Luciane P.; CARVALHO, Fátima M. A. A construção civil como instrumento do desenvolvimento da economia brasileira. Revista Paranaense de Desenvolvimento, n.109, p.9-26, jul/dez 2005.

TREVISAN CONSULTORES. Estudo setorial da construção civil. 2007. Disponível em: <http:www.trevisanconsult.com.br/pdf/estudosetorialconstrucaocivil. pdf $>$. Acesso em jun.2009.

VAN DER MERWE, Anton. Debating the principles: ABC and its dominant principle of work. Cost Management, v.23, n.5, p.20-28, Sep/Oct 2009.

WAWERU, N. M.; HOQUE, Z.; ULIANA, E. A survey of management accounting practices in South Africa. International Journal of Accounting, Auditing and Performance Evaluation, v.2, n.3, p.226-263, 2005.

YIN, Robert, K. Estudo de caso: Planejamento e Métodos. $3^{\mathrm{a}}$ Ed. Porto Alegre: Bookman, 2005. 
